\title{
A descolonização da palavra
}

Francisco Soares ${ }^{1}$

Tradicionalmente a palavra poética refaz uma ligação essencial, perdida ou simplesmente oculta, restaurando portanto o sentido e a visão do mundo. Apesar disso, cada comunidade com perfil e história próprios usa palavras diferentes. Quando duas tradições entram em choque ou em diálogo - o que sempre aconteceu na história da humanidade - é comum que ambas sofram algum descondicionamento, dando-nos a linguagem e as artes sinais correspondentes e que, por sua vez, são participantes ativos nesse descondicionamento. Quando o processo é vivido com mais intensidade (por exemplo quando os contextos são plurilinguísticos) assemelha-se ao que, na psicologia da criatividade, é justamente a fase mais criativa, que nos liberta para o maior número de perspetivas possiveis. É um momento chave e, por isso, quando há uma interação forte entre duas ou mais culturas, assistimos a um crescimento da originalidade artística e linguística. Ele foi, por exemplo, sentido vigorosamente no período helénico no Mediterrâneo, o mesmo que viu crescer a influência da Bíblia, o sincretismo religioso, as 'novelas' e, eventualmente, o 'romance', a par das primeiras manifestações conhecidas, no que à Europa diz respeito, do que hoje chamamos poesia visual - então ainda articulada a um sentido religioso do oculto.

As novas literaturas africanas, particularmente as lusófonas, encontram-se distribuídas por vários graus de intensidade dos

\footnotetext{
${ }^{1}$ Professor da Universidade Agostinho Neto, em Angola. Conferência pronunciada em Barcelona, nas Jornades de Literatures Africanes "Äfrica son Veus", realizada de 20 a 22 de Abril de 2009, pelo Institut Catalunya-Africa. O texto foi re-escrito para a presente edição da revista Crioula.
} 
processos de descondicionamento a que me refiro. Num dos graus mais elevados e mais turbulento está a literatura angolana. Este texto pensa a temática da criatividade verbal em contextos multiculturais $\mathrm{e}$ plurilinguísticos como o helénico, o angolano e o do atual processo de globalização de mercados e culturas. Dessa forma pensa também na equivalência entre a descolonização do pensamento e o descondicionamento das palavras

\section{Instantâneos}

Acalmai-vos

Fragmentadores alados do crepúsculo

Eu sou a Palavra

A abóboda celeste

O encontro dos espaços

(Ruy Duarte de Carvalho)

Desmantelado, eu sobreviverei apenas no precário registo das palavras

(Rui Knopfli)

Os excertos acima citados são diferentes. A diferença que entre eles me interessa relaciona-se com o facto de o primeiro se dirigir a nós na pretensão de recuperar uma perspetiva tradicional. Aí a palavra, ou a voz, é lugar de encontro em função de uma verdade absoluta que representa, que mais precisamente encarna, incorpora; ela representa o exercício das coincidências que repõem, por via da linguagem, a verdadeira e única ordem do mundo. O segundo excerto antevê um nãosujeito, na medida em que ausente e fragmentário, um não-sujeito que, no entanto, ficou ainda registado na precariedade verbal. $\mathrm{O}$ primeiro representa, para mim, uma conceção colonial ou colonizada da palavra poética; o segundo está mais próximo de representar um pensamento 
descolonizado sobre a poesia, ainda que nele a palavra possua resquícios de um papel passivo, representativo.

A minha posição parece estranha, mas não é. Na verdade, quando se fala na descolonização da palavra o pensamento imediato reporta-se, não propriamente a um processo de descolonização cultural, mas a um processo de recolonização cultural. Explico-me: imaginando, como normalmente se faz, que temos de um lado uma língua e uma cultura não colonizadas e, de outro lado, uma língua e uma cultura coloniais, a descolonização da palavra consistiria em trazer para a língua do colonizador a cultura e, pelo menos em parte estruturante, os esquemas principais da língua do colonizado. É um mecanismo simples de raciocínio que, por isso mesmo, se propaga sem pensarmos muito nele. É por isso o protótipo seguido nas conferências que falam sobre poesia e descolonização. Vale a pena, portanto, analisá-lo, desmontá-lo, descolonizá-lo.

Em primeiro lugar é preciso pensarmos que não temos de um lado uma língua e uma cultura (a do colonizado), do outro lado outra cultura e língua (a do colonizador). Em muitos países, como é o caso de uma parte significativa de Angola (particularmente significativa para a nossa expressão literária), temos um demorado confronto e convívio entre os dois lados. Não há, portanto, dois centros propulsores de cultura e lingua, mas um centro transicional, híbrido, com uma extrema e rápida mobilidade, que absorve, transforma, rejeita e negoceia constantemente as culturas em convivio ou contradição. Tal centro é a pessoa, uma pessoa essencialmente urbana. Por isso é que se dá a colonização e a descolonização da palavra e pela palavra: porque há um sujeito em transição que leva e traz, de umas para outras línguas, em sentidos diversos, sintaxes e lexemas que vão desconstruirse e reconstruir-se uns nos outros ou com os outros. Quer isso dizer que a pessoa a que me refiro é uma espécie de língua intermédia, que não chega a constituir-se como lingua mas opera sintática e imagisticamente ligando os dois polos anteriores. Uma espécie de pidgin 
ou crioulo meramente mental, pré-verbal, cuja sintaxe e cuja imagística, porém, condicionam as diversas colonizações das palavras.

Verificando agora os tais polos é preciso compreender o seguinte: que não há uma língua do colonizado, mas várias. Embora no caso de Angola tenhamos sobretudo variações das línguas bantos, há línguas pré-bantos em ação também e há, não só variações linguísticas, também culturais. As línguas bantos, por sua vez, não chegaram ao fim do século XV, nem a 1975, isentas de contaminações as mais diversas. Por sua vez, a língua do colonizador - no nosso caso o português - foi colonizada ao longo dos séculos e gerou-se a partir do mesmo tipo de pidgin ou crioulo mental, pré-linguístico. Nela encontramos palavras árabes, gregas, germânicas, celtas, berberes, novilatinas e não apenas latinas. É com essa língua que desembarcam no Kongo os marinheiros portugueses e, nos seus navios, não seguiam só portugueses. Seguiam também marinheiros de outros países, sobretudo europeus (italianos, espanhóis, dos vários reinos da Hespanha). Igualmente foram por ali pregando padres portugueses, italianos, hespanhóis - sobretudo estes. O português falado por eles estava já crioulizado nas paragens mais a norte, não só na Europa (em Nápoles, por exemplo), mas ainda no arquipélago de Cabo Verde e nas ilhas culturais da Senegâmbia. Portanto, as linguas dos colonizados e as línguas dos colonizadores não se apresentaram como uma só, nem num estado puro, anterior a qualquer interferência. Pelo contrário, fizeram-se e desenvolveram-se diversificando-se num quadro de invasões, conquistas, migrações, convivios e confrontos, mais ou menos forçados, mais ou menos harmonizados.

Nesse aspeto, a palavra a descolonizar foi na verdade criada numa dinâmica de colonizações em que, tanto o colonizado quanto o novo conquistador, incidiam sobre ela disputando as marcas a instilar, cravando-lhe significados, traços semânticos, sintáticos, rítmicos e outros. Quando chegamos à independência, as nossas palavras estavam já razoavelmente colonizadas por nós. Falo de nós, os angolanos. E digo que tal processo continua. De maneira que não se trata da 
descolonização da palavra, mas sim de confronto e de convivio entre genealogias lexicais e estruturais, numa dinâmica fortemente imprevisível, onde cada movimento de descondicionamento coincide com o contrapolar movimento de recondicionamento.

Por um lado, isso levou-nos a ter uma aguda consciência da mobilidade, da fluidez e da precariedade das palavras e das línguas; por outro lado levou-nos a muitas vezes pensar que o nosso trabalho poético se reduziria a enxertar na estrutura óssea ou ossificada da lingua portuguesa uma semântica banto. O primeiro lado conduz-nos a uma constante e instigante criatividade a todos os niveis, mantendo o português de Angola, o angolês se quisermos, numa espécie de mercado paralelo onde cada genealogia comercial, politica, antropológica, disputa o seu espaço de manobra e o seu perfil de presença e de mistura. A postura em aberto que vigora aí tem no processo criativo uma função fundamental: a de nos manter abertos a muitas hipóteses, traduzindo com liberdade aceções e experimentando verbalmente possibilidades até, por vezes, contraditórias. É desse caldo linguístico que surgem as obras mais significativas de Luandino Vieira e de Uanhenga Xitu, mais recentemente de António Azzevas e Ondjaki.

O segundo 'lado' é o que aborda geralmente dizendo que o colonizado vai descolonizar a língua do colonizador colonizando-a com a sua. É um bocado esquizofrénico e fica-se por aí. Perante uma possibilidade de abertura, faz-nos recuar para a mera troca de um por outro colonialismo verbal. Apenas nos diz que a palavra que repõe a ordem do mundo, para nós, tem que ser esta e não aquela. Pressupõe, no entanto, que ela existe (a palavra da verdade), a par da ordem que repõe. Para tais escritores a língua, bem como o estilo e a forma, destinam-se apenas a veicular a ordem, a regularidade, enfim a verdade. São meros instrumentos da maravilhosa coincidência entre o que se diz e o que se passa numa ordem oculta aos olhos comuns ou não doutrinados. Herdaram tal postura do velho realismo socialista e aplicam-na hoje a um discurso etnicista muito mal fundamentado. Repetirão os erros da maioria das escolas literárias: hão de levar o seu 
modelo à exaustão, o que é fácil e, não reconhecendo o fracasso ou o esgotamento da proposta, tentarão impedir que os jovens (e alguns menos jovens) partam por outros caminhos à procura das palavras independentes.

São estas que, porém, nos interessam. O escritor colonizado, ou simplesmente extraeuropeu, sentiu muito mais os maleficios do colonialismo linguístico e duma visão ditatorial do que há de ser a linguagem poética. Sentiu-a pela opressão e pelo branqueamento cultural que o colonialismo trouxe consigo. Sentiu-a depois pela promoção de um discurso unívoco no tempo do partido único. Revoltando-se contra as suas limitações, descobriu a liberdade e o seu potencial criativo revelou-se vigorosamente; descobriu também as virtudes, criativas e não só, da diversidade e inscreveu no próprio discurso literário as alteridades coexistentes, coniventes ou paradoxais. Apesar do sofrimento, a circunstância colocou-o numa situação que será, cada vez mais, a dos escritores em todo o mundo. A posição dos escritores atuais não é inédita na própria Europa (lembremo-nos do período helenístico e alexandrino, para citar apenas um exemplo). Não sendo no entanto inédita atinge nos nossos dias uma intensidade nunca antes vista e que vinha sendo preparada a par do (inicialmente) lento processo de globalização das economias e dos mercados. Citando Mayra Santos-Febres, "como dijera Borges en el 1932, en El escritor argentino y la tradición, los escritores latinoamericanos, al ser marginales, recombinamos la tradición. Lo hacemos tensamente, inseguramente, con otra perspetiva "2.

Veja-se que a globalização, inevitavelmente, gera ondas de transformação para fora e para dentro dos países, por assim dizer, globalizadores. Lembremo-nos de como na Europa cada revolução literária (Renascimento, Romantismo, Modernismos) se seguiu a um período de expansão transcontinental. Isso, a par da aceleração nas

2 "Lo universal", artigo saído no jornal El país, suplemento "Babelia", http://www.elpais.com/articulo/semana/universal/elpepuculbab/20090328elpbabese_1/Tes (última consulta: 3-4-2009). 
comunicações e da abertura criada pelo avanço tecnológico, vem colocar os escritores de hoje face aos desafios de uma diversidade instigante, que se lhes impõe por dentro das próprias palavras. Este instante pode ser aproveitado para, precisamente, descolonizar o pensamento descondicionando as palavras, jogando o jogo do seu choque, da sua fragmentação, desmontagem, libertação. Ao que vimos assistindo, principalmente desde o século XX, é justamente à descolonização mental dos colonizadores, não só dos colonizados. Acabaremos por descobrir todos que o velho discurso que nos foi vendido ou imposto era velho e falsificava mesmo os escritores dos países que o promoveram. Daí que, tanto colonizados recentes quanto colonizadores recentes, tenhamos promovido, por múltiplas vias, uma implosiva libertação das palavras, de que o concretismo foi o mais ilustrativo caso.

Também vemos acontecer essa implosão criativa nos poetas angolanos revelados após a independência - e o processo começara já com David Mestre, Arlindo Barbeitos, Ruy Duarte de Carvalho principalmente estes, embora sinais viessem de trás, esparsos, tímidos ainda. Implodem-se as lógicas autoritárias e coloniais nas metáforas ousadas, de grande leque, inusitadas e cheias de propriedade, que podemos ler na lírica de José Luís Mendonça. Por exemplo em "Catembe":

Meilitro de palheto e uma coca-cola

É a medida certa que o oceano trasfega

Em nossas barrigas de funge e carapau.

Neste tempo de candonga catembe é o mais santo

Estase de sábado. A televisão vai dando

Missa de Elton John que nós somos mesmo

Universais pela picada impoluta

Do dólar e da cultura nacional.

Só as kalashnikovs paridas em 61

Desconhecem a química do Catembe:

Vão-se alfabetizando enquanto folheiam

Nossas barrigas de funge e carapau. 
Também a vemos no jogo de repetições e variações que tão bem carateriza a poesia de João Maimona, próxima do poema-processo de Mário Chamie, em que o retorno de cada palavra ao texto vem trazer-lhe uma aceção nova, da qual se parte para outra ainda, numa simultaneidade de identificações e afastamentos potencialmente infinita. Leia-se o breve poema "Saudável saudação":

Minha erguida cidade ou tarde de cacimbo:

Vem torturar-me o incansável pé: repito de pé

Sempre que deixo a cama da perversão.

Por outra via o angolês explode liricamente nas aliterações, implosões lexicais e ambivalências de Lopito Feijoo. Recordo-me de poemas como "Meditando":

- engoli de um espinheiro um grande raminho -

$\&$

da tese concebida ao prefácio por escrever teço toc toc enquanto toco levemente o porvir d'outra gestão

daí a cor do sangue escasso caro irmão protestante que tão bem partes os passeios que passeio assim que passo passo a passo me ditando!

Finalmente podemos participar dessa implosão na desmontagem exata e eximia da sintaxe, gerando segmentos frásicos plurifuncionais, promovida por Abreu Paxe. Por exemplo em "Descontrução castrada":

re-elaboro o riso nódoas num pouco de noite caem desamparadas dois crepúsculos balcões contemporâneos em alta fraga o pátio utilidades os elementos primordiais quatro desconstroções castrada boca sinal quando se integra 
Sei que resumi tudo a 4 autores, o que é sem dúvida injusto para os não-citados. A minha preocupação foi a de propor uma abertura, uma foz à qual possam chegar as outras experiências contemporâneas, deixando portanto ao leitor a descoberta desse vasto oceano migratório.

Benguela - Évora, Janeiro - Março 2009 